Opinion

\section{Coronaryvirus infection, oxidative stress in ENT}

\author{
Holeček $\mathbf{V}^{1 *}$ and Rokyta $\mathbf{R}^{2}$ \\ ${ }^{1}$ Department of Clinical Chemistry, Mulac Hospital, Pilsen, Czech Republic \\ ${ }^{2}$ Charles University, Thirth Faculty of Medicine, Department of Physiology, Prague, Czech Republic
}

\section{Introduction}

In COVID-19 pandemic we focused on epidemiology and somewhat we neglect the possibility of biochemical influencing of the infection. Therefore we try to find some properties of the virus, which are impressionable by drugs. Droplet infection transmission is mainly (hypochloric acid) by nose and mouth. Diseases of nose and paranasal sinuses are most often of viral or bacterial origin.

\section{Properties of coronaryvirus}

COVID-19 is a single-branched RNA, it does not mutate quickly. It is quite capable on external influences and hates heat and frost. In external environment will last only a few dozen minutes, but in the room even some days. Ordinary disinfections easily inactivate coronaryvirus. Also $\mathrm{HClO}$ exhibit anti-influent virus activity.

Infections are of different gravity, from common cold to pneumonia to multiorgan failure and death. Severe course of the disease is in $14 \%$, critical course in $4 \%$ cases.

COVID-19as many other virus infections produces oxidative stress, i.e. superiority of free radicals over antioxidants. Free radicals have one or more non-pared electrons, which attracts another electron from the surrounding. So the substrate is oxidised (lipoperoxidation, oxidation of proteins, of DNA and RNA, etc.). Sometimes we use the expression ROS (reactive oxygen species) which except free radicals includes substances which don't correspond we the definition of free radicals, but act like them (singlet oxygen, ozone, hydrogen peroxide). The reason of these virus reactions are energy profit and penetration through the membranes into tissues (sinuses, lungs, kidneys etc., harmfully acts on lymphatic and vascular endothel). Free radicals in WBC's kill bacterias, but on virus infections have opposite influence. Oxidation of biomoleculs depends on redox potential. Substance with higher redox potential can oxidise substances with lower potential which have prooxidative action. Redox potential of antioxidants must be sufficiently low, otherwise they will act proxidatively.

\section{More Information}

*Address for Correspondence:

Václav Holeček, Department of Clinical

Chemistry, Mulac Hospital, Pilsen,

Czech Republic, Email: vholecek@volny.cz

Submitted: 09 September 2020

Approved: 16 September 2020

Published: 17 September 2020

How to cite this article: Holeček V, Rokyta R. Coronaryvirus infection, oxidative stress in ENT. Heighpubs Otolaryngol Rhinol. 2020; 4: 021-022.

DOI: 10.29328/journal.hor.1001022

Copyright: @ 2020 Holeček V, et al. This is an open access article distributed under the Creative Commons Attribution License, which permits unrestricted use, distribution, and reproduction in any medium, provided the original work is properly cited.

Check for updates

OPEN ACCESS
Virus is under different pressures. Evolutionarily convenient is for him not to kill to much patients and so infected people can disseminate viruses and on the other hand is the pressure to maintain mutations, which will improve the ability of transmission. The amount of COVID-198 virusis during the first week is high, the second week it decreases, therefore the therapy must start quicly.

Another property of coronavirus is "cytokine storm“. It is a strong immunite reaction, which releases many cytokines into the blood, with inflammation, cytopenia, hyperferritinemia, increased nitroxide formation and free radicals formation. Free radicals formed in cytokine storm are factors executing direct damage of cells and tissues. Cytokines work as signalization molecules. NO is mediator of hypotension caused by IL-2. IL- 6 and TNF $\alpha$ (tumor necrosis factor) support the creation of superoxide in neutrophils. The combination of free radicals due to cytokine storm with external or internal production of free radicals and with diseases which have increased level of free radicals (diabetes, renal insufficiency, neurodegenerative diseases, tumors, necrosis of WBC etc.) are especially dangerous for the patients. Increased creation of free radical are also due to negative emotions, anxiety, and pain. In the brain they accumulate during the day, the sleep neutralizes them and then acts as antioxidant. People with coronaryvirus infection sometimes loose taste and smell, very probably due to the damage of receptors by free radicals. People used a high level of free radicals like smokers, athlets (muscle load) or alcoholics (reperfusion after hypoxia) can have light course of the disease. 
Oxidative stress caused by COVID-19 activates antioxidative defense of host cells for its own protection. Increased balance between proteasis/antiproteasis with benefit to proteasis leads to propensity of respiratory diseases.

Children are more resistant to COVID-19. They have high level of antioxidant melatonin, which is produced during sleep. Coenzym Q10 inibits lipoperoxidation of mitochondia. Therapy by SOD (superoxid dismutase) a by high doses of vitamin $\mathrm{C}$ and by glutathion are tested.

\section{Possible antioxidative therapy}

1) Defend multiplication of COVID-19.

Antioxidant flavonoid taxifolin may be useful. NO inhibits synthesis of virous protein and RNA. Greater danger of COVID-19 infection is for old people. Aging decreases total antioxidant capacity, zinc and selenium. Substitution of them may improve the indurance of old people against COVID-19.

2) Limit the mutation of RNA and DNA by free radicals. The defense against mutated viruse is less effective. Second wave of infections is possible. Antioxidants may help.

3) Kill the viruses and so prevent latent infection. Probably persistence of positive test is due it. Even we cannot exclude the possibility of repeated infection. The therapy includes UVB rays, combination of antioxidants, umbilicant stem cells, vaccination etc. 